[18] Sangrasi, A. K., Talpur, K. A. H., Kella, N., Laghari, A. A., Abbasi, M. R., Qureshi, J. N. (2013). Role of laparoscopy in peritonitis. Pakistan Journal of Medical Sciences, 29 (4), 1028-1032. doi: http://doi.org/ $10.12669 /$ pjms. 294.3624

[19] Dellinger, R. P. (2003). Cardiovascular management of septic shock. Critical Care Medicine, 31 (3), 946-955. doi: http://doi.org/10.1097/01.ccm.0000057403.73299.a6

[20] Rivers, E., Nguyen, B., Havstad, S., Ressler, J., Muzzin, A., Knoblich, B. et. al. (2001). Early Goal-Directed Therapy in the Treatment of Severe Sepsis and Septic Shock. New England Journal of Medicine, 345 (19), 1368-1377. doi: http://doi.org/10.1056/nejmoa010307

[21] Ronco, C., D'Intini, V., Bellomo, R. et. al. (2005). Rationale for the use of extracorporeal treatments for sepsis. Anesthesiology and Reanimatology, 5, 87-91.

[22] Rhodes, A., Evans, L. E., Alhazzani, W., Levy, M. M., Antonelli, M., Ferrer, R. et. al. (2017). Surviving Sepsis Campaign: International Guidelines for Management of Sepsis and Septic Shock: 2016. Intensive Care Medicine, 43 (3), 304-377. doi: http://doi.org/10.1007/s00134-017-4683-6

\title{
EVALUATION OF THE INTERNAL PICTURE OF HEALTH IN PATIENTS WITH ACUTE CORONARY SYNDROME IN PRESENTING WITHOUT ST-SEGMENT AFTER PERCUTANEOUS CORONARY INTERVENTIONS AND IN THE PROCESS OF REHABILITATION
}

\author{
Roxolana Nesterak \\ Departament of internal medicine No. 2 and nursing \\ Ivano-Frankivsk National Medical University \\ 2 Halytska str., Ivano-Frankivsk, Ukraine, 78018 \\ roxolana.nesterak@gmail.com
}

\begin{abstract}
Ischemic heart disease remains an actual problem of modern clinical and rehabilitation medicine. One of the forms of ischemic heart disease (IHD) is an acute coronary syndrome (ACS) in patients presenting without persistent ST-segment, the treatment of which involves the use of conservative treatment and reperfusion techniques. An integral part of the management of patients after acute coronary syndrome is rehabilitation and restoration with the search for methods of changing the attitude of the patient to his health. To improve the rehabilitation of patients it is important to assess the internal picture of health with the formation of the correct attitude of the patient to his health.

Aim. To study the peculiarities of the components of the internal picture of health in patients with acute coronary syndrome in patients presenting without persistent ST-segment in the process of treatment and rehabilitation.

Materials and methods. There were examined 135 patients with ACS presenting without persistent ST-segment, who were divided into the groups depending on the treatment performed; 60 patients with conservative treatment tactics and 75 patients with the performed PCI. The analysis of the internal picture of health was carried out with the help of methods: hospital scale for the detection of anxiety and depression (HADS); patient health questionnaire (PHQ-9); scale for measuring the level of reactive (situational) and personality anxiety of Spielberg-Hanin; SF-36; indicators of the Seattle Quality of Life Questionnaire for Patients with Angine Pectoris (Seattle Angina Questionnaire - SAQ).

Results. The study of the internal picture of health in patients with ACS presenting without persistent ST-segment showed low levels of emotional, sensory, cognitive, value-motivational, behavioral components on the appropriate scales, which also depend on the method of treatment used. The revealed peculiarities of patients with ACS presenting without persistent ST-segment need to increase the knowledge of the patient about the disease and the importance of rehabilitation measures.

Conclusions. In assessment of the internal picture of health in patients with ACS presenting without persistent ST-segment after transcutaneous coronary intervention and in the process of rehabilitation, it has been determined that the course of ischemic heart disease in patients with ACS presenting without persistent ST-segment, both during conservative treatment and in the course of PCI at the stages of rehabilitation, is accompanied by significant changes of the internal picture of health (IPH); the most significant changes in patients with ACS presenting without persistent ST-segment is the value-motivational and behavioral components of the
\end{abstract}


internal picture of health. In order to increase the effectiveness of rehabilitation after ACS, it is advisable to apply programs that will significantly affect the positive changes in the rehabilitation of patients with ACS.

Keywords: acute coronary syndrome, rehabilitation, internal picture of the patient's health, depression, quality of life.

\section{Introduction}

Ischemic heart disease remains an actual problem of modern clinical and rehabilitation medicine.

One of the forms of IHD is ACS presenting without persistent ST-segment, which has a mortality rate similar to the ACS with elevation of ST segment in the distant terms, which causes not only attention to the data of patients in the acute phase, but also in the long-term period of observation and rehabilitation $[1,2]$.

Treatment of patients with ACS is performed using conservative treatment and revascularization of the myocardium, through percutaneous coronary intervention (PCI) and aortic coronary intervention (CABG) [3]. The use of PCI promotes the positive dynamics of IHD symptoms with the improvement of the life quality, its duration, and contributes to improvement of the ability of patients to work $[4,5]$.

An integral part of the management of patients after acute coronary syndrome is rehabilitation and restoration. In many studies, the effectiveness of cardiological rehabilitation in the reduction of the mortality rate in patients with acute coronary syndrome and after coronary artery bypass surgery is determined, but there is a necessity to find ways to improve it in patients with various manifestations of IHD [6, 7].

Psychological symptoms are prevalent for people with CHD, and many psychological treatments are offered following cardiac events or procedures with the aim of improving health and outcomes $[8,9]$. Psychological interventions reduced the risk of cardiac deaths and reduced participant-reported symptoms of depression, anxiety, and stress [10].

Particular attention deserves knowledge and awareness of patients about the risk of cardiovascular disease, if the patient does not have information about the disease, he can not understand and change his attitude to these factors [11].

The internal picture of the patient's health (IPH) is a special relation to his health, which is expressed in the awareness of its value and active-positive striving for its recovery and improvement. IPH is always adjusted by the complexity, the level of life threatening, social adaptation, etc. The way to reduce the impact of the disease on the quality of life of a person - is to correct the intellectual ideas about the present state of health and the future prospects of recovery, a set of measures about the control of emotional experiences and feelings about the symptoms of the disease, as well as building a system of behavior for the preservation and restoration of health $[12,13]$.

Therefore, in order to improve the rehabilitation of patients after acute coronary syndrome, it is necessary to seek methods for assessment of the internal picture of health with the formation of the correct attitude of the patient's health.

\section{Aim of research}

To analyze the peculiarities of ACS presentation without persistent ST-segment on the basis of the evaluation of the components of the internal picture of health and the search for new personalized methods for improving the management of patients at the stage of rehabilitation and restorative post-infarction period

\section{Materials and methods of the research}

The research was conducted on the basis of the infarct department No. 2 and rehabilitation of the Ivano-Frankivsk Regional Clinical Cardiology Center, from 2015 to 2018 years.

There were examined 135 patients with ACS presenting without persistent ST-segment who were divided into groups depending on the performed treatment; 60 patients who were performed 
conservative treatment tactics and 75 patients who were performed PCI. The average age in the group of patients with conservative treatment was $68.38 \pm 1.30$ years, and in the group of patients who had PCI $-64.70 \pm 1.65$ years.

The internal picture of health was evaluated according to 5 components: emotional, sensory, cognitive, value-motivational, behavioral, using the values of the respective scales.

Indicators of the emotional components of the internal picture of health were interpreted by the Hospital Anxiety and Depression Scale (HADS); Patient Health Questionnaire-9-PHQ-9 and the Relactivel (Situational) and Personal Anxiety Scale of Spielberg-Hanin. The determination of the life quality (36-Item Short Form Health Survey (SF-36) was performed using the scales - "Social Functioning" (SF), "Role Emotional Functioning" (Role Emotional -RE), and "Mental Health" (Mental Health - MH).

Indices of the sensitive components of the internal health picture were obtained according to the "Seattle questionnaire of life quality for angina pectoris patients" (Seattle Angina Questionnaire - SAQ) and its Scales of "Physical Load Limitation" (Physical Limitation - PL), "Stability of angina pectoris" (Angina Stability - AS), "Frequency of attacks"(Angina Frequency - AF), and SF-36 scales: "Physical Functioning" (Physical Functioning - PF), "Intensity of pain" (Bodily Pain - BP), "Social Functioning" (Social Functioning - SF).

The cognitive component was determined on the basis of the "Seattle Angina Questionnaire for the patients with angina pectoris" (SAQ): Treatment Satisfaction (TS), Disease Perception (DP), and SF-36 Scale "General Health Condition" (General Health - GH).

The value-motivational component of the internal health picture was analyzed according to SF-36 scale "Vitality" (Vitality - VT), the definition of the behavioral component - according to the scale SF-36: "Role Physical Functioning" (RP), "Role Emotional Functioning" (RE) and Social Functioning (SF).

The survey was performed during the first week after admission to the Cardiology Center, and the data was filled in by the patients independently in the presence of a doctor or a psychologist.

Interpretation of the results was performed in points, according to each method. Hospital scale for the detection of anxiety and depression (HADS): 0-7 points - norm, 8-10 points - subclinically expressed anxiety/depression (mild), 11 points and above - clinically expressed anxiety/ depression; the patient's health questionnaire (PHQ-9): 0-4 - there is no depression, 5-9 - mild "subclinical", 10-14 - of submoderate severity, 15-19 - of moderate severity, 20-27-severe depression; scales of reactive (situational) and personality anxiety of Spielberg-Hanin: up to 30 points low anxiety, from 31-45 points - average, more than 45 points - high level of anxiety. The encoding of SF-36 responses was standardized within the range of 0-100, where 100 points represents complete health. The Seattle Quality Questionnaire for Angina Pectoris Patients (Seattle Angina Questionnaire - SAQ), depending on the answer to the question, was determined from 1 to 5 points, followed by recalculation.

All patients received standard therapy for patients with IHD in accordance with recommendations European Society of Cardiology (ESC), conservative treatment with antiplatelet medicines (acetylsalicylic acid, thienopyridine derivatives), anticoagulants (unfractionated heparin, low molecular weight heparins), anti-ischemic therapy (beta-blockers, nitrates), statins, ACE inhibitors. The PCI was in coronary angiography and stenting of the infarct-dependent coronary artery [14].

The obtained results were statistically processed by the methods of variation statistics (arithmetic mean, standard error, mean square deviation, confidence interval). The probability of differences between the compared groups was determined using the Student's t-test. Statistical testing of hypotheses to determine the differences between nonparametric features was performed using $\chi 2$-criterion and z-criterion. Correlation analysis was carried out based on determining the parametric correlation coefficient. The reliability of the correlation connection was assessed according to Student's criterion. The results were statistically plausible with $p<0.05$. Maintaining the databank of study, basic calculations of derivative indicators, frequency characteristics of signs, construction of diagrams were performed by the software Microsoft Access, Microsoft Excel 2010 (license number 01631-551-3027986-27852) 


\section{Results}

Analyzing the indicators for assessment of the emotional component of the IPH, it was found that in both groups of patients with ACS presenting without persistent ST-segment there were high levels of anxiety and depression, according to the HADS scale. The same levels of depression were determined according to the questionnaire of PHQ-9 in patients with conservative treatment and in patients with PCI.

In the analysis of indicators of reactive anxiety levels in patients with ACS presenting without persistent ST-segment were observed high levels in the group who had conservative treatment and who were performed PCI (Table 1).

\section{Table 1}

Indices of assessment of the emotional components of IPH in patients with ACS presenting without persistent ST-segment, depending on the used methods

\begin{tabular}{ccc}
\hline \multirow{2}{*}{ Questionnaires, points } & \multicolumn{1}{c}{ Patients with ACS presenting without persistent ST-segment } \\
\cline { 2 - 3 } & Conservative treatment & PCI \\
\hline Level of anxiety & $8.27 \pm 1.8$ & $8.32 \pm 1.9$ \\
Level of depression & $6.82 \pm 1.7$ & $6.42 \pm 1.6$ \\
& PHQ-9 & $5.92 \pm 2.0$ \\
\hline Level of depression & $6.16 \pm 2.3$ & $46.8 \pm 1.19$ \\
& Questionnaire of Spielberg-Hanin & $46.7 \pm 1.18$ \\
Reactive anxiety & $45.9 \pm 1.20$ & $53.9 \pm 2.5^{*}$ \\
Personal anxiety & $47.6 \pm 1.19$ & $45.7 \pm 4.8$ \\
Social functioning & SF-36 & $48.1 \pm 1.9$
\end{tabular}

Note: Reliability of difference of indicators: $*_{-}<0.05$

The reactive anxiety depended on the subjective perception of the treatment results, therefore, in the group with the use of PCI there are lower levels of anxiety than in the group of conservative treatment, due to the fact that life threatening and the necessity for PCI increase reactive anxiety. The level of personal anxiety was high in patients with ACS presenting without persistent ST-segment in the group of conservative treatment and in patients who had PCI.

According to the scale "Social Functioning" (SF), the following changes were observed. Patients who had conservative treatment, noted that the disease limits social activity, patients who had PCI also experienced limitations in social functioning; however, they were more positive at restoration of social activity, respectively $(45.9 \pm 2.9)$ and $(53.9 \pm 2.5)$ points $(\mathrm{p}<0.05)$.

The "Scale of Role Emotional" (RE) assesses the extent to which an emotional state interferes with the performance of day-to-day activities. Low rates according to this scale are noted in both observation groups, which is associated with diminished opportunities in daily activities and a negative impact on the emotional state. Patients who have received conservative treatment tactics, noted that they needed to cope with the disease, and patients who were performed PCI are more optimistic, faster changes give hope for overcoming of the disease and its consequences.

Assessing the presence of anxiety and mood on both according to the HADS scale and to the "Mental Health Scale" (MH), somewhat higher rates were observed in a group of patients who were performed PCI. 
The evaluation of the sensitive component of PCI in patients with ACS presenting without persistent ST-segment, according to the SAQ questionnaire, showed that the limitation of physical activity in both groups was respectively in patients with conservative treatment and in patients who had PCI $(\mathrm{p}<0.05)$.

The indicators according to the scale "Angina Stability" and "Angina Frequency" were low.

By analyzing quality of life indicators, a difference between the indices, depending on the chosen treatment tactics, was found (Table 2). The higher indices according to the "Physical Functioning" (PF) scale were in patients with PCI, along with low rates in the group of patients with conservative treatment tactics due to the age of the patient, the severity of the disease, stay in the department of anesthesiology and intensive care with the chambers of intensive care, minor sensations of improvement of the clinical condition, the necessity for long-term treatment $(\mathrm{p}<0.05)$.

\section{Table 2}

Indices of evaluation of the sensitive component of IPH in patients with ACS presenting without persistent ST-segment, depending on the applied method of treatment

\begin{tabular}{ccc}
\hline \multirow{2}{*}{ Questionnaires, points } & \multicolumn{2}{c}{ Patients with ACS presenting without persistent ST-segment } \\
\cline { 2 - 3 } & Conservative treatment & PCI \\
\hline PAQ & $57.9 \pm 2.6^{*}$ \\
Angical Limitation & $50.1 \pm 2.8$ & $54.2 \pm 4.2$ \\
Angina Frequency & $48.0 \pm 4.0$ & $48.0 \pm 3.5$ \\
\hline Physical functioning & $42.0 \pm 3.1$ & $52.4 \pm 2.8^{*}$ \\
Bodily Pain & SF-36 & $50.1 \pm 1.9^{*}$ \\
Social functioning & $44.0 \pm 3.0$ & $53.9 \pm 2.5^{*}$
\end{tabular}

Note: Reliability of difference of indicators: $*_{-}<0.05$

Patients with ACS presenting without persistent ST-segment with conservative treatment according to their subjective score according to the scale of "Bodily Pain" (BP), a significant effect of the disease on the daily activities and limitation of the activity of patients were revealed. The patients who had PCI were more positive about their condition and pain sensations, because the intervention had a rapid effect and reduced the character of pain sensations $(p<0.05)$.

Analyzing the cognitive components of IPH in patients with ACS presenting without persistent ST-segment (Table 3), it was found that most patients are satisfied with the treatment.

Table 3

Indices of the assessment of the cognitive component of IPH in patients with ACS presenting without persistent ST-segment, depending on the applied methods

\begin{tabular}{ccc}
\hline \multirow{2}{*}{ Questionnaires, points } & \multicolumn{2}{c}{ Patients with ACS presenting without persistent ST-segment } \\
\cline { 2 - 3 } & Conservative treatment & PCI \\
\hline SAQ & $62.0 \pm 2.2$ \\
Dreatment Satisfaction & $61.4 \pm 2.0$ & $48.0 \pm 2.5$ \\
\hline General health & $47.8 \pm 2.7$ & \\
\hline SF-36 & $38.9 \pm 2.1$ & $45.3 \pm 2.0^{*}$
\end{tabular}

Note: Reliability of difference of indicators: $*_{-}<0.05$ 
According to the scale of the attitude to the disease, the low rates were both in the group of patients with conservative treatment and in the group with PCI, patients need additional knowledge about the disease, which will contribute to a more informed patient's attitude to his condition, optimization of IPH and active participation of the patient in the process of rehabilitation and restoration.

According to the "General Health Condition" (GH) scale, assessing from the perspective of future treatment, it has been stated that patients who were performed conservative treatment, show distrust of recovery, do not mark the dynamics of changes between the state of the attack and the current state, with some distrust of the treatment. Higher indices according to the scale (GH) were in patients with performed PCI and associated with greater faith in recovery, a sense of progress in treatment and a higher degree of adherence to treatment $(\mathrm{p}<0.05)$.

Assessment of the value-motivational and behavioral components of IPH in patients with ACS presenting without persistent ST-segment showed their decrease. The low indicators according to the scale "Vitality" (VT) were found both in the group of conservative treatment $(49.8 \pm 2.6)$ points and in the group with PCI (51.4 \pm 2.4$)$ points. All the worries about the disease, the assistance provided, the feeling of fear experienced, and the reduction of physical strength have led to changes in both physical and emotional levels and a decrease in vital activity. According to these indicators one can state the fear of the patient for the future, the necessity for long-term rehabilitation and change in the way of life (Table 4).

\section{Table 4}

Indices of the assessment of the value-motivational and behavioral components of IPH in patients with ACS presenting without persistent ST-segment, depending on the used method of treatment

\begin{tabular}{ccc}
\hline \multirow{2}{*}{ Questionnaires, points } & \multicolumn{2}{c}{ Patients with ACS presenting without persistent ST-segment } \\
\cline { 2 - 3 } & Conservative treatment & PCI \\
\hline SF-36 & $51.4 \pm 2.4$ \\
\hline Vitality & $49.8 \pm 2.6$ & $48.4 \pm 3.0^{*}$ \\
\hline Role Physical Functioning & Behavioral component & $45.7 \pm 4.8$ \\
Role Emotional & $39.3 \pm 3.2$ & $53.9 \pm 2.5^{*}$
\end{tabular}

Note: Reliability of difference of indicators: * ${ }_{-}<0.05$

The decrease of the indicators according to the scale "Role Physical Functioning" in patients with ACS presenting without persistent ST-segment with conservative treatment (39.3 \pm 3.2$)$ points, suggest that patients in this group are more limited in their daily activities $(\mathrm{p}<0.05)$.

The score according to the scale "Role Emotional" in patients with ACS presenting without persistent ST-segment with conservative treatment was (42.5 \pm 5.0$)$ points, in the group of patients with ACS presenting without persistent ST-segment, who were performed PCI, respectively (45.7 \pm 4.8$)$ points and are those indicating the absence of desire and motivation to perform work in patients of both groups.

Also, changes were observed in both groups according to the scale of "Social functioning", which indicates a reduced value-motivational and behavioral attitude of patients. Under such changes, patients are reluctant to participate in all components of rehabilitation treatment.

The levels of formation of each component of the internal picture of health IPH in patients with ACS presenting without persistent ST-segment, depending on the used method, are given in Table 5, 6. 
Table 5

Levels of formation of the IPH components in patients with ACS presenting without persistent ST-segment, who were provided conservative treatment tactics (n-60)

\begin{tabular}{|c|c|c|c|c|c|c|c|c|c|c|}
\hline \multirow{3}{*}{$\begin{array}{c}\text { Level of } \\
\text { components' } \\
\text { development }\end{array}$} & \multicolumn{10}{|c|}{ Component of IPH } \\
\hline & \multicolumn{2}{|c|}{ Emotional } & \multicolumn{2}{|c|}{ Sensitive } & \multicolumn{2}{|c|}{ Cognitive } & \multicolumn{2}{|c|}{ Value-motivational } & \multicolumn{2}{|c|}{ Behavioral } \\
\hline & $\mathbf{n}$ & $\%$ & $\mathbf{n}$ & $\%$ & $\mathbf{n}$ & $\%$ & $\mathrm{n}$ & $\%$ & $\mathbf{n}$ & $\%$ \\
\hline Low & 23 & 38.3 & 21 & 35.0 & 18 & 30.0 & 29 & 48.3 & 30 & 50.0 \\
\hline Middle & 28 & 46.7 & 31 & 51.7 & 32 & 53.3 & 24 & 40.0 & 22 & 36.7 \\
\hline High & 9 & 15.0 & 8 & 14.3 & 10 & 16.7 & 7 & 11.7 & 8 & 14.3 \\
\hline
\end{tabular}

Note: the absolute number of patients is indicated; the percentage to the absolute number of patients is given

In patients with ACS presenting without persistent ST-segment with conservative treatment tactics, low and average levels of formation of all components of IPH were revealed; in half of patients, the value-motivational and behavioral components are of low levels of formation, respectively, $48.3 \%$ and $50.0 \%$. The same peculiarities are observed in the group of patients with ACS presenting without persistent ST-segment, who were performed PCI (Table 6).

\section{Table 6}

Levels of formation of the IPH components in patients with ACS presenting without persistent ST-segment who were performed PCI (n-75)

\begin{tabular}{|c|c|c|c|c|c|c|c|c|c|c|}
\hline \multirow{3}{*}{$\begin{array}{c}\text { Level of } \\
\text { components } \\
\text { development }\end{array}$} & \multicolumn{10}{|c|}{ Component of IPH } \\
\hline & \multicolumn{2}{|c|}{ Emotional } & \multicolumn{2}{|c|}{ Sensitive } & \multicolumn{2}{|c|}{ Cognitive } & \multicolumn{2}{|c|}{ Value-motivational } & \multicolumn{2}{|c|}{ Behavioral } \\
\hline & $\mathbf{n}$ & $\%$ & $\mathbf{n}$ & $\%$ & $\mathbf{n}$ & $\%$ & $\mathbf{n}$ & $\%$ & $\mathbf{n}$ & $\%$ \\
\hline Low & 25 & 33.3 & 19 & 25.3 & 20 & 26.7 & 33 & 44.0 & 34 & 45.3 \\
\hline Middle & 36 & 48.0 & 41 & 54.7 & 39 & 52.0 & 32 & 42.7 & 30 & 40.0 \\
\hline High & 14 & 18.7 & 15 & 20.0 & 16 & 21.3 & 10 & 13.3 & 11 & 14.67 \\
\hline
\end{tabular}

Note: the absolute number of patients is indicated; the percentage to the absolute number of patients is given

\section{Discussion}

Acute coronary syndrome remains an urgent problem of the present, and the choice of the correct tactics for the management of such patients can have a significant effect on the reduction of mortality [15].

ACS presenting without persistent ST-segment in the long dates (after 6 months) has mortality indices similar to ACS with ST-segment elevation, which causes not only attention to these patients in the acute phase, but - in the long-term period of observation and rehabilitation [16].

Patients with ACS had high levels of anxiety somewhat higher level of anxiety was observed in patients with PCI $(8.32 \pm 1.9)$ points, and in patients with conservative treatment $(8.27 \pm 1.8)$ points. The level of depression was observed somewhat higher in patients with ACS presenting without persistent ST-segment with conservative tactics $(6.82 \pm 1.7)$ points in the conservative treatment and $(6.42 \pm 1.6)$ points in patients with PCI, respectively.

In the analysis of indicators of anxiety levels, according to the questionnaire of Spielberg-Hanin, the levels of reactive anxiety in patients with ACS presenting without persistent ST-segment who had conservative treatment, high levels $(45.9 \pm 1.20)$ of points were observed, in the group of patients with ACS presenting without persistent ST-segment, who were performed PCI $(46.8 \pm 1.19)$ points. The level of personal anxiety was high in patients with ACS presenting without persistent ST-segment in the group with conservative treatment $(47.6 \pm 1.19)$ points and in patients who had PCI (46.7 \pm 1.18$)$ points. 
The indicators or the quality of life according to the SAQ questionnaire, showed that the limitation of physical activity in both groups was $(50.1 \pm 2.8)$ points in patients with conservative treatment and $(57.9 \pm 2.6)$ points, in patients who had PCI respectively $(\mathrm{p}<0.05)$. According to the SF-36, indicators quality of life were similar, the "Physical Functioning" scale showed higher indices in patients with PCI (52.4 \pm 2.8$)$, alongside with low rates in the group of patients with conservative treatment tactics - $(44.0 \pm 3.0)$ points.

These changes need a complex approach with the use of clinical and psychological evaluation, especially on the stage of rehabilitation of the patients with ACS.

Correction of psychological disorders is an integral part of rehabilitative measures [17]. Under the influence of a combination of factors in patients, an internal picture of health is formed which is an important component in adapting to new conditions of existence, in particular, after suffered acute coronary syndrome during the phase of rehabilitation [18].

Internal picture of health - is a subjective reflection of the person's state of health, its components are distinguished (sensitive, emotional, cognitive, value-motivational, and behavioral), and the influence on them allows optimization of the IPH and building of individual work with the patient, tracing the dynamics and the effectiveness of changes [19].

Along with the evaluation of clinical, objective and psychometric data, it is necessary to find new methods for assessment and influence on the components of the internal health picture and the development of methods for the improvement of the restorative period after acute coronary syndrome.

The impact on the components contributes to the search for human efforts and specific actions, driven by the knowledge and decision-making system and aimed at the achievement of the health rehabilitation goals. The behavioral level of the internal picture of health is associated with the actualization of human activities for the preservation of health, it is the highest level of attitude to health, therefore, it requires vigorous activity of the person, aimed at preservation and maintaining his/her health [20].

The revealed changes in the internal picture of health in patients with ACS without elevation of ST segment need to expand the knowledge of the patient about the disease and the importance of rehabilitative measures. The necessity for compliance and implementation of these measures will enhance the level of motivation and positively influence the behavior of patients. It is because of the sensory, emotional, and cognitive components of IPH, a positive behavioral effect can be obtained from the treatment and the effectiveness of rehabilitation of patients after ACS can be improved.

Such changes in the internal picture of health in patients with ACS presenting without persistent ST-segment need to increase the knowledge of the patient about the disease and the importance of rehabilitation measures. The necessity for compliance and implementation will contribute to raising the level of motivation and positively affect the behavior of patients. It is because through the sensory, emotional, and cognitive components of IPH, a positive behavioral effect can be obtained from the treatment and the effectiveness of rehabilitation of patients after ACS can be improved.

It is promising to the development of programs for medical-psychological rehabilitation, taking into account the forms of occurrence of coronary artery disease and applied methods of diagnosis and treatment, in particular in patients with conservative treatment, thrombolytic therapy or invasive tactics.

\section{Conclusion}

1. The course of IHD in patients with ACS presenting without persistent ST-segment, both in the conservative treatment, and in the course of PCI in the stages of rehabilitation, is accompanied by significant changes in IPH, which determine the effectiveness of restorative treatment of patients.

2. The most significant changes in patients with ACS presenting without persistent ST-segment are according to the value-motivational and behavioral components of the internal picture of health, which depend on the applied method of treatment.

3. In order to increase the effectiveness of rehabilitation after ACS, it is advisable to use programs aimed at optimization of the IPH.

4. Implementation and evaluation of the effectiveness of the programs for the optimization of IPH will significantly affect the development of positive changes both in the early post-infarction period, and will help to improve the long-term results of rehabilitation of patients with ACS. 


\section{References}

[1] Aglullin, E. I. (2013). Acute coronary syndrome: from diagnosis to optimization of treatment. Vestnik sovremennoy klinicheskoy meditsiny, 6 (5), 91-94.

[2] Veauthier, B., Sievers, K., Hornecker, J. (2015). Acute coronary syndrome: out-of-hospital evaluation and management. FP Essent, 437, 11-6.

[3] Lie, I., Arnesen, H., Sandvik, L., Hamilton, G., Bunch, E. H. (2010). Predictors for Physical and Mental Health 6 Months After Coronary Artery Bypass Grafting A Cohort Study. European Journal of Cardiovascular Nursing, 9 (4), 238-243. doi: http://doi.org/10.1016/j.ejcnurse.2010.02.001

[4] Sokolov, M. Yu. et. al. (2016). Registry of percutaneous coronary interventions: a comparative analysis of 2014-2015. Regional reperfusion networks in Ukraine - the dynamics of development. Sertse i Sudyny, 3, 14-34.

[5] Barna, M. B., Alifer, O. O., Novitska, A. M. (2015). Assessment of life quality in patients with chronic non-infectious diseases. Liky Ukrayiny, 4 (25), 9-12.

[6] Abreu, A. (2017). CROS editorial comment: Cardiac rehabilitation effectiveness in the "new era": Any doubts after an acute coronary event? European Journal of Preventive Cardiology, 24 (8), 796-798. doi: http://doi.org/10.1177/2047487317694468

[7] Sawatzky, J.-A. V., Kehler, D. S., Ready, A. E., Lerner, N., Boreskie, S., Lamont, D. et. al. (2014). Prehabilitation program for elective coronary artery bypass graft surgery patients: a pilot randomized controlled study. Clinical Rehabilitation, 28 (7), 648-657. doi: http://doi.org/10.1177/0269215513516475

[8] Albert, M. A., Durazo, E. M., Slopen, N., Zaslavsky, A. M., Buring, J. E., Silva, T. et. al. (2017). Cumulative psychological stress and cardiovascular disease risk in middle aged and older women: Rationale, design, and baseline characteristics. American Heart Journal, 192, 1-12. doi: http://doi.org/10.1016/j.ahj.2017.06.012

[9] Albus, C., Ladwig, K.-H., Herrmann-Lingen, C. (2014). Psychokardiologie: praxisrelevante Erkenntnisse und Handlungsempfehlungen. DMW - Deutsche Medizinische Wochenschrift, 139 (12), 596601. doi: http://doi.org/10.1055/s-0033-1360102

[10] Richards, S. H., Anderson, L., Jenkinson, C. E., Whalley, B., Rees, K., Davies, P. et. al. (2017). Psychological interventions for coronary heart disease. Cochrane Database of Systematic Reviews. doi: http:// doi.org/10.1002/14651858.cd002902.pub4

[11] Pogosova, N. (2017). Infarction and stroke - not a sentence, they can be prevented. Moskovskaya meditsina, 4 (19), 26-30.

[12] Nesterak, R. V., Gasyuk, M. B. (2017). Pilot investigation of the method of interactive training of patients at the stage of medical rehabilitation and treatment Deutscher Wissenschaftsherold. German Science Herald, 4, 38-41.

[13] Program of psychological rehabilitation of cardiologic patients by optimization of the internal picture of health (2017). Author's Certificate No. 75681 dated 29.12.2017.

[14] Roffi, M., Patrono, C., Collet, J.-P., Mueller, C., Valgimigli, M., Andreotti, F. et. al. (2015). 2015 ESC Guidelines for the management of acute coronary syndromes in patients presenting without persistent ST-segment elevation: Task Force for the Management of Acute Coronary Syndromes in Patients Presenting without Persistent ST-Segment Elevation of the European Society of Cardiology (ESC). European Heart Journal, 37 (3), 267-315. doi: http://doi.org/10.1093/eurheartj/ehv320

[15] Dubikaitis, T. A. (2017). Acute coronary syndrome. Russian Family Doctor, 21 (1), 5-14. doi: http://doi.org/10.17816/rfd201715-14

[16] Aglullina, E. I. (2013). Acute coronAry syndrome: from diAgnosis to treA tment optimizA tion. The Bulletin of Contemporary Clinical Medicine, 6 (5), 91-94. doi: http://doi.org/10.20969/vskm.2013.6(5).91-94

[17] Pająk, A., Jankowski, P., Kotseva, K., Heidrich, J., de Smedt, D., De Bacquer, D. (2012). Depression, anxiety, and risk factor control in patients after hospitalization for coronary heart disease: the EUROASPIRE III Study. European Journal of Preventive Cardiology, 20 (2), 331-340. doi: http://doi.org/ $10.1177 / 2047487312441724$

[18] Hasiuk, M. B., Nesterak, R. V. (2018). Internal picture of the health of patients who experienced ischemic heart disease and myocardial infarction: an empirical study. Naukovyy visnyk Khersonskoho derzh. universytetu, 2 (2), 149-155.

[19] Lisova, O. S. (2002). Internal picture of health. Psychology. Collection of scientific works. NPU named after MP Drahomanov, 15, 69-77.

[20] Nikiforov, G. S. (2002). Psychology of health. Saint Petersburg: Rech, 256. 